\title{
Spinal anesthesia for Cesarean delivery in obese parturients: is this the best option?
}

\author{
Stephen Halpern, MD, MSc, FRCPC (1)
}

Received: 18 March 2018/Revised: 19 March 2018/Accepted: 19 March 2018/Published online: 26 April 2018

(c) Canadian Anesthesiologists' Society 2018

\section{To the Editor,}

A recent study in the Journal by George et al. ${ }^{1}$ compared two methods of preventing hypotension related to spinal anesthesia for Cesarean delivery in the obese parturient. In a well-conducted randomized-controlled trial, one group received bolus doses of phenylephrine while the other received a continuous infusion. The study was important because the primary outcomes of nausea and vomiting were patient-centred and address patient comfort. Nevertheless, in both groups, the incidence of intraoperative nausea and vomiting related to hypotension remained high. While the incidence of hypotension was reduced in the infusion group, the incidence of maternal hypertension and bradycardia was increased.

What can we learn from this? Perhaps spinal anesthesia is not the best option for the obese population. Epidural anesthesia, titrated through an epidural catheter, has the advantage of a slower onset time that may allow for the patient's compensatory mechanisms to work, reducing the need for vasopressors and swings in blood pressure. In normal obstetric populations, the neonatal acid-base balance may be better in patients who received epidural anesthesia compared with those who received spinal anesthesia. ${ }^{2}$ In addition, neuraxial anesthesia can be technically difficult in the morbidly obese patient, but if epidural anesthesia is chosen instead, a higher, more accessible interspace can be chosen without fear of spinal cord damage. Finally, epidural anesthesia has the advantage of allowing the patient to take their time to position themselves on the operating table before drug administration. This would avoid potential back strain injury to staff ${ }^{3}$ and positioning injuries to patients. These advantages may well be worth the few extra minutes that it may take to obtain surgical anesthesia in this epiduralbased anesthetic population.

Conflicts of interest None declared.

Editorial responsibility This submission was handled by Dr. Hilary P. Grocott, Editor-in-Chief, Canadian Journal of Anesthesia.

\section{References}

1. George RB, McKeen DM, Dominguez JE, et al. A randomized trial of phenylephrine infusion versus bolus dosing for nausea and vomiting during cesarean delivery in obese women. Can J Anesth 2018; 65: 254-62.

2. Reynolds F, Seed PT. Anaesthesia for caesarean section and neonatal acid-base status: a meta-analysis. Anaesthesia 2005; 60: 636-53.

3. Hammond $K L$. Practical issues in the surgical care of the obese patient. Ochsner J 2013; 13: 224-7.

This letter is accompanied by a reply. Please see Can J Anesth 2018; 65: this issue. 